\title{
REINFORCING RIGHT TO LIFE UNDER THE LENS OF PALLIATIVE HEALTHCARE IN INDIA ${ }^{1}$
}

DOI:10.47743/rdc-2021-1-0007

Soham KULKARNI

\section{ABSTRACT}

Provisions to a dignified end to life definitely must be a concern that our constitutional founders had in mind while framing the foundation of our nation. The term "Palliative care" was coined much later. The WHO defined palliative care as "an approach that improves the quality of life of patients and their families facing the problems associated with life-threatening illness, through the prevention and relief of suffering by means of early identification and impeccable assessment and treatment of pain and other problems, physical, psychosocial, and spiritual". The Government of India formed a committee in 2006 to create a national policy for palliative care. However, even after the being hit by Coronatimes, the National Policy for palliative care has not seen the light of the day. In view of the above, the study aims to explore Palliative Care under the provisions of Article 21 and other fundamental rights; it aims to interrogate the aspect of 'dignity'; the role of the Government; evolution of the field through judicial proceedings; legal position in other jurisdictions of the world and an urgent need to reinforce "Palliative healthcare" in India.

Keywords: palliative healthcare, role of government, right to life

\section{Introduction}

Dr. Balfour Mount First coined the term Palliative Care in 1973. This discipline of medicine has evolved over time and is unique in its features as it involves a multidisciplinary approach involving physicians, nurses, psychologists, and physiotherapists along with other specialties as when indicated. The goal of palliative care is to improve the quality of life physical as well as psychological factors for patients and their families. The deep impact of the illness on the close relatives and primary caregivers has been recognized with mitigation of the fear of death, for both also being a focus.

\footnotetext{
${ }^{1}$ Presented at the International Conference on "Multidisciplinary Facets for Development in Health Laws", organized by Manipal University Jaipur India School of Law in collaboration with Bio Forensics Research Center, Italy, 16-17 July 2021.

${ }^{2}$ First Year LLB at MIT WPU.
} 


\section{Reinforcing right to life under the lens of palliative healthcare in India}

Palliative care and hospice care are further regarded as near but different fields. While hospice care concentrates on comfort at the end of life, palliative care is broader in its impact on society as it focuses on chronic illnesses where life expectancy is fairly long and the individual's social functionality, psychosocial pain mitigation, productivity, longevity and spirituality are all focused upon.

The median age in India is 26.8 years currently and is estimated to be 38.1 years by 2050 with an elderly population (60 years plus) of over 178.59 million by $2031^{3}$. A significant burden of comorbidities like diabetes, heart disease, stroke, cancer and other disabilities will burden the elderly according to the national sample survey ${ }^{4}$. Combining the shift in population dynamics and high comorbidity ratios the level of quality of life and the need for palliative care cannot be stressed enough. The aspect of dignity of life corelated to constitutional framework, outlook of government and grants to promotion and research in the palliative care field as well as the legal position of the judiciary on the subject is explored.

\section{Discussion and analysis}

According to the World Bank statistics in 2018, India, the world's second most populated country at 1.39 billion inhabitants spends about $3.54 \%$ of its GDP on healthcare ${ }^{5}$. The average a country spends on healthcare is $8.8 \%$ of the GDP. The Economic survey noted that actual allocation of the expenditure resources towards healthcare when scrutinized came to about $0.34 \%$ of the GDP while the remaining were spent on important items but parallel to mainstream healthcare items ${ }^{6}$. The 2017 National Health Policy recommends minimum spending of 2.5 to $3 \%$ of the GDP on items directly related to healthcare and healthcare research. Now, in 2021, due the impact of the pandemic, the government of India has declared a budget promising to spend $2,23,846$ crore rupees on healthcare equivalent to 2.5 to $3 \%$ of the GDP as per the 2017 National Health Policy recommendations thus giving the sector a center stage in budget allocation?. According to these figures, it becomes necessary to explore where palliative care stood in the governmental framework of the ministry of health and family welfare and through which programs it is implemented.

In 2006 the Government of India formed a committee to create a national policy for palliative care. In 2008 the government in collaboration with WHO experts formed guidelines for the development and implementation of palliative care across India.

\footnotetext{
${ }^{3}$ India - Median Age of the Population 1950-2050 | Statista, n.d.

${ }^{4}$ Current Health Expenditure (\% of GDP) - India | Data, n.d.

${ }^{5}$ Current Health Expenditure (\% of GDP) - India | Data, n.d.

${ }^{6}$ Explained: Despite Govt Claims, India's Health Budget Only Around 0.34\% of GDP - The Wire Science, n.d.

${ }^{7}$ Healthcare Sector: Hits \& Misses from Budget 2021 - Times of India, n.d.
} 
The National program for palliative care was established in 2012 under the National Health Mission and implemented under National Programme for Prevention and Control of Cancer, Stroke (NPCDCS), CVD and Diabetes. A similar style of implementation was seen when earlier the health ministry modified its National Cancer Control Program in 1980s to make pain relief a basic service. However, over time the pain relief took a back seat and other services assumed primacy. Currently palliative care no longer assumes a manual or guideline under NPCDCS ${ }^{8}$.

Article 21 of the Indian Constitution reads that "No person shall be deprived of his life or personal liberty except according to a procedure established by law".

Initially, in A.K Gopalan vs. State of Madras, the Supreme Court interpreted the words 'procedure established by law' through the English concept of personal liberty with legislature being supreme to the judiciary ${ }^{9}$. This caused a narrow interpretation of the applicability of one the most important fundamental rights.

Much later in 1971 in the case of Maneka Gandhi vs. Union of India, the Supreme Court took a different view and Article 21 assumed a broader perspective ${ }^{10}$.

Held: the right to life as enshrined in Article 21 of the Constitution of India means more than survival or animal existence and would include the right to live with human dignity. It would include the right to minimum subsistence allowance and all those aspects which will make a man's life meaningful, complete and worth living.

Ten years later, in 1981, in the case of Francis Coralie Mullin vs. Administrator, Union territory of Delhi and Ors., the essence of Maneka Gandhi case was reiterated in the words of Justice P.N. Bhagwati "The fundamental right to life which is the most precious human right and which forms the ark of all other rights must therefore be interpreted in a broad and expansive spirit so as to invest it with significance and vitality which may endure for years to come and enhance the dignity of the individual and the worth of the human person"11.

In Olga Tellis and Ors. vs. Bombay Municipal Corporation and Ors., a bench headed by Justice Chandrachud, while interpreting Article 21 held that "No individual can barter away the freedoms conferred upon him by the Constitution. The right to life can only be taken away or abridged by a procedure established by law, which has to be fair and reasonable, not fanciful or arbitrary"12.

In the case of Subhas Kumar vs. The State of Bihar in 1991, it was held that the right to life also included the right to pollution free water and healthy air ${ }^{13}$.

Currently Article 21 has been developed into a wide view by the judiciary by cross-linkage to Article 19 of the Constitution. Among the different rights under

\footnotetext{
${ }^{8}$ Khosla, Patel \& Sharma, 2012.

${ }^{9}$ A.K. Gopalan vs. The State of Madras. Union of India on 19 May, 1950, n.d.

${ }^{10}$ Maneka Gandhi vs. Union of India on 25 January, 1978, n.d.

${ }^{11}$ Francis Coralie Mullin vs. The Administrator, Union Union Territory for Delhi on 13 January 1981, n.d.

12 Olga Tellis \& Ors. vs. Bombay Municipal Corporation \& Ors. on 10 July 1985, n.d.

${ }^{13}$ Subhash Kumar vs. State of Bihar and Ors. on 9 January 1991, n.d.
} 
Article 21 recognized by the law, the right to health, the right to medical care and the right to die are upheld by palliative care along with the aspects of personal liberty as well as dignity in healthcare procedure. Under the universal declaration of human rights, Article 21 and the right to health has been interpreted in accountability, accessibility, equality and as universally indivisible and interdependent. Every individual regardless of their economic conditions should get access to healthcare as a fundamental right. The healthcare systems shall be accountable, and the State shall be accountable to make the system. The right to medical care includes equality and non-discrimination, not just in treatment but also in basic hygiene, food and housing ${ }^{14}$.

Lastly, the right to die can be said to be impacted the maximum by good palliative care practices in India. In India the suicide rate has been increasing. Of the 8 lakh cases of suicide every year, $17 \%$ are occurring in India. As per the statistics, illness and prolonged illness cause nearly 39,165 suicide deaths annually, becoming the largest contributors of suicide in India. These lives can be saved by good pain control and psychological support.

In Gian Kaur vs. State of Punjab, it was held that; right to life does not contain the right to die, it contains protection of life and the right to live with dignity up to natural death and includes a dignified procedure of death ${ }^{15}$.

In M.S. Dubal vs. State of Maharashtra, it was held that right to life brings into its purview not to live a forced life, however, euthanasia was not legalized as it involves a third person and would attract section 306 of IPC ${ }^{16}$.

In March 2018, in the landmark judgement of Aruna Ramchandra Shanbaug vs. Union of India, the honorable Supreme Court observed that there is no statutory provision as to the legal procedure for withdrawing life support to a person in a permanent vegetative state or who is otherwise incompetent to take a decision in this connection. The five-judge constitutional panel of the Supreme Court gave a legal sanction to passive euthanasia. It allowed the concept of 'living will' by permitting withdrawal of life support if they slip into coma. The right to die with dignity was finally held as a fundamental right ${ }^{17}$.

As evidenced above, the question of right to live with dignity and die with dignity comes into focus when an individual is afflicted with disability, pain, societal pressure and their family reels under the psychosocial pressure seeing a close one being slowly physically incapacitated due an illness. Main focus of Palliative care is to protect life by keeping an individual free from all the above-mentioned issues and when such a protection is not possible, protect the right to die with dignity by allowing the individual to make an informed decision well in advance. It aims at absorbing the evils

\footnotetext{
${ }^{14}$ Asthana, 2020.

${ }^{15}$ Smt. Gian Kaur vs. The State of Punjab on 21 March, 1996, n.d.

${ }^{16}$ Maruti Shripati Dubal vs. State of Maharashtra, n.d.

${ }^{17}$ Aruna Ramchandra Shanbaug vs. Union of India \& Ors. on 7 March, 2011, n.d.
} 
in the procedure of death and focuses on the rights and needs of the individual as well as family. Thus, Palliative care in many instances starts well before the individual reaches a point close to death and tries to improve the longevity while maintaining the dignity and quality of life. It truly interprets Article 21 as more than mere survival and animal existence keeping intact the basic features essential for human existence.

The major hurdle in the development of palliative care has been the Narcotic Substances and Psychotropic Substances (NDPS) act of India brought out in 1985. This led to reduced availability of morphine. Thus, the palliative care approach and features in National Cancer Control Program failed due to legal hurdles in availability of drugs. In 1998 the government of India directed the State governments to amend the narcotics regulations but the response was poor. Only $3 \%$ of Cancer patients gained access to proper analgesics until 2014. Thus, progress of the government in the field halted. However, the medical fraternity felt the strong need for palliative care and a number of NGOs cropped up during the 1980s and 90s. The most notable being the IAPC: Indian association of palliative care came to be registered in 1994 in Ahmedabad. A movement in the field was started with Kerala, NCR Delhi, Gujarat and states taking the lead. Throughout this timeframe, the government continued to give palliative care but only in select district hospitals. In 2001, WHO with other international organizations took the lead through the Neighborhood Network of Palliative Care (NNPC), a joint venture which developed sustainable and low-cost palliative care for all. Hospice care also developed through the Indian Red Cross, Guwahati pain and palliative care society and Chandigarh pain and palliative care services.

In 2008, Kerala became the first State to announce a palliative care policy and by 2012 upwards of 138 centers for palliative care came to be established across 16 States and union territories with the Medical Council of India recognizing a specialization in palliative care as a separate field ${ }^{18}$.

Finally, the NDPS act of 1985 was amended in 2014. The amendment transferred the power to regulate possession, transport, purchase, sale, import inter-state, export inter-state, use or consumption of essential narcotic drugs from the States to the central government. It made available morphine, codeine, fentanyl, methadone and other essential pain-relieving drugs to registered and licensed practitioners to prescribe the same to patients. Further amendments were done to the NDPS act and online sales of certain drugs were allowed in the 2019 amendment. Following these amendments, State laws changed and palliative care nursing homes could be registered under acts such as the Bombay Nursing Home Act. Likewise, geriatric facilities came to be allowed as an amenity and could be constructed in amenity spaces in townships. Assisted living facilities were legalized ${ }^{19}$.

\footnotetext{
${ }^{18}$ Khosla, Patel \& Sharma, 2012.

${ }_{19}$ 158504.Pdf, n.d.
} 
Reinforcing right to life under the lens of palliative healthcare in India

A constitutional interpretation paving way for changes in central, State and local laws can be made out over the timeline of roughly 40 years.

\section{Conclusion}

Sticking to the initial interpretation of Article 21 would mean conducting a host of medical experiments on a human being with the sole outcome of longevity. However, the aspect of personal liberty and dignity in life and death embedded through the interpretation of Article 21 by the court has given the true meaning to the right to life. The subsequent upheaval of private individuals and organizations forcing the legislature to amend draconian laws and thus paving the way for a pain free end to life is a dream in the making. The Corona virus pandemic has forced war like situations on the healthcare front where many could not gain access to medical care. Medical triage had to be performed where life of one had to be chosen over another. Palliative care was essential in providing comfort to the ones that could get access to it where lifesaving drugs or equipment were not available and to the ones where, even in availability, they could not protect life. Many families too were helped by this branch of medicine to ease their trauma and guide them through the procedure of death.

Perhaps our leaders have felt the strong need of the soothing touch required for the ones at the end of life and families who then will have to start again in a new world. That is why as a ray of hope, Palliative Care finds its place in the budget 2021 declared by the finance minister in February 2021. At the backdrop of the pandemic, the government expenditure on healthcare promises to see a $137 \%$ rise. Pradhan Mantri Atmanirbhar Swasth Bharat Yojana which will run parallel to National Health Mission and has been given a grant of 64 thousand crores with a vision to setup 1.5 lakh health and wellness centers across India, both urban and rural over six years. Palliative Care finally finds place in the form of one of the 12 packages declared under this scheme. Thus, we may find a dedicated National health program for Palliative Care soon. We can only hope that the 40 years of struggle by judiciary, government, international organizations, NGOs, medical professionals and medical organizations will culminate in truly upholding the right to life, right to medical aid and the rights to die with dignity for all citizens of our great nation. 